ORIGINAL ARTICLE

\title{
Intended 3D conformal irradiation of internal mammary lymph node is better than incidental irradiation in breast cancer patients.
}

\author{
Yousra Taha El-Drgham, Ahmad AL-hosainy, Heba Mounir,Mohammed Fathy Bayomy \\ Clinical Oncology and Nuclear Medicine, Faculty of Medicine, Zagazig University.
}

\begin{abstract}
Corresponding author: Mohammed Fathy Bayomy

(Lecturer of Clinical Oncology and

Nuclear Medicine, Faculty of

Medicine, Zagazig University), mohammed_Fathy29121981@yah oo.com, mobile number:
\end{abstract}

$\begin{array}{ll}\text { Submit Date } & 2019-07-06 \\ \text { Revise Date } & 2019-07-23 \\ \text { Accept Date } & 2019-07-27\end{array}$

\begin{abstract}
Background: Internal mammary lymph node irradiation is a matter of debate.

Aim of work: was to make a dosimetric comparison between two different approaches for internal mammary lymph node volume irradiation.

Methods: prospective study was conducted in the Zagazig University Clinical Oncology and Nuclear Medicine Department. 38 patients with breast cancer presented in the period between March 2017 to March 2019. After finishing conformal three dimensional radiotherapy planning for breast cancer, we delineated internal mammary lymph nodes volume. Incidental internal mammary irradiation plan was the conventional tangential fields that cover chest wall or whole breast volume. Intended internal mammary irradiation plan was wide tangential fields that cover internal mammary lymph nodes volume.

Results: Average of mean dose to internal mammary lymph nodes volume was significantly increased from $4581 \mathrm{cGy}$ in incidental plan to $5213.6 \mathrm{cGy}$ in intended plan $(\mathrm{p}<0.001)$. Average of V40 of heart volume was significantly increased from $10.8 \%$ in incidental plan to $12 \%$ in intended plan $(\mathrm{p}=0.002)$.
\end{abstract}

Conclusion: Incidental treatment of internal mammary lymph nodes was insufficient to properly treat it. Intended plan was capable to improve dose coverage of internal mammary lymph nodes.

Keywords: Internal mammary lymph node; Incidental; Intended;

Breast cancer; Radiotherapy.

\section{INTRODUCTION}

B reast cancer is the first most common cancer in women according to the National Cancer Registry Program (20082011). Breast cancer constitutes $32.04 \%$ of all women cancers. In Egypt, breast cancer incidence in 2015 was 19,411 new cases involving 19,105 women and 306 men (1). Breast-conserving surgery in addition to postlumpectomy whole breast radiotherapy is the optimal treatment of early stage breast cancer to reduce breast cancer recurrence in the same breast (2). Post-modified radical mastectomy radiotherapy certainly reduces the frequency of local and regional recurrence and improves overall survival, especially in breast cancer patients with high risk features. Current recommendation is to deliver radiotherapy for women with T3 primary tumors and/or three or more positive axillary lymph nodes patients (3). The second draining pathway of breast cancer is internal mammary lymph nodes (IM). Involvement of axillary lymph nodes raises possibility of IM involvement as patients with negative axillary nodes, have probability of $4-9 \%$ to have positive IM nodes while patients with axillary positive nodes, have probability of $16.52 \%$ to have positive IM nodes (4). Huang and his colleagues studied 2269 breast cancer patients who operated by extended radical mastectomy without any neoadjuvant treatment from 1956 to 2003, their aim was to determine the patient subpopulation with high risk of 
internal mammary lymph nodes metastasis. They categorized patients into five groups of patients with more than twenty percent probability of internal mammary lymph node spread, (A) Patients with medial tumour and positive axillary nodes, (B) Patients with 4 or more positive axillary nodes, (C) Patients with T2 tumour and positive axillary LN, (E) Patients with T2 tumour and medial tumour, and (E) Patients with T3 tumour and less than 35 years (5). Internal mammary lymph node irradiation is a matter of debate where postmastectomy or post-lumpectomy radiotherapy to the chest wall and/or breast and axillary and/or supraclavicular lymph nodes was shown to improve overall survival in early breast cancer (6). In EBCTCG metaanalysis, there was no benefit for radiotherapy in patients with node-negative disease while $7.9 \%$ absolute reduction at twenty years in patients with 1-3 positive axillary lymph nodes and found $9.3 \%$ reduction in patients with 4 or more positive axillary nodes (7). Incidental irradiation of lymph node can be occured during conformal three-dimensional chest wall and/or breast irradiation (8). Our study wasn't done to add any benefit to body of literature about internal mammary lymph node irradiation indications or technique but it was actually to get a practical proof about necessity to change out of departmental practice "'not to treat internal mammary lymph node whether there is indication for that or not, because our fear from lungs and heart toxicity'. We were hoping to answer these questions: can we consider a considerable dose is delivered to internal mammary lymph nodes without its contouring and optimization of plan to include it so no need to optimize plan that may affect more lung and heart tissue (as in RTOG contouring guideline there a considerable overlap between IMLN volume and chest wall/whole breast volume)?, if we need to contour it and optimize plan using wide tangential field, is wide tangential field technique can adequately achieved using our current resources of conformal radiotherapy planning and delivery tool with acceptable toxicity profile?. So our study aim was to make a dosimetric comparison between two different approaches during conformal three dimensional radiotherapy planning of locoregional irradiation of postmastectomy and postlumpectomy sittings. Primary objective of current study to make a dosimetric comparison between incidental and intended internal mammary irradiation regarding dose volume histogram parameters of internal mammary lymph nodes (IMLN) clinical target volume (CTV). Secondary objective was to make a dosimetric comparison between incidental and intended internal mammary irradiation regarding dose volume histogram parameters of ipsilateral lung, contralateral lung, total lung and heart.

\section{SUBJECTS AND METHODS}

This prospective dosimetric study was conducted in the Zagazig University Clinical Oncology and Nuclear Medicine Department in period between March 2017 to March 2019. Written informed consent was obtained from all participants and the study was approved by the research ethical committee of Faculty of Medicine, Zagazig University. The work has been carried out in accordance with The Code of Ethics of the World Medical Association (Declaration of Helsinki) for studies involving humans. Sample size was calculated by Open Epi, version 2 based on result of Leite ETT, et al. study (9) where mean of D95 (cGy) were $228.1 \pm 136.6$ and $733 \pm 766$ cGy. Thirty eight patients had a pathological diagnosis of invasive breast carcinoma either underwent modified radical mastectomy or breast conservative surgery and high-risk stage I-II disease or stage III disease (patients with indication of postoperative irradiation) had included in our study. Patients with distant metastasis were excluded. For all study patients, the following data was reported; medical history, pathological findings based on histopathological specimens (excisional biopsy and surgical specimen), clinical examination includes general examination and local examination. Bilateral mammography and ultrasonography were requested. Plain X-ray or chest computed tomography (CT) with contrast is requested if 
indicated. Pelvi-abdominal U/S or CT pelviabdomen with contrast was also requested if indicated. Bone scintigraphy was requested if indicated. Echocardiography was requested for all patients to document ejection fraction prior to chemotherapy and to exclude any preexiting cardiac issues. Regarding laboratory investigations, complete blood picture, liver function test, kidney function test as a requirement for chemotherapy and tumor markers include CA15-3 and CEA were requested. Immobilization of all patients were done by using a breast board (Generic board locally manufactured to mimic brand CIVCO $^{\circledR}$ breast board) followed by CT scanning (Philips conventional $50 \mathrm{~cm}$ pore CT scanner) with slices thickness of $5 \mathrm{~mm}$ start at $5 \mathrm{~mm}$ intervals from top of thyroid notch to 5 $\mathrm{cm}$ below contralateral inframammary fold. Automatic transfer of CT images to a treatment planning system (TPS) (PrecisePLAN Release 2.12 - 477.08) silicon graphic workstation (CPU ID: 1762688860) was achieved. Delineation and contouring included the CTV and relevant organs-at-risk (OARs) were according to the Radiation Therapy Oncology Group (RTOG) recommendations (10). Tangential fields were designed upon planning target volume based on the delineated target volumes. Wedges and field-in-field strategies were used. Dosevolume histogram was obtained to optimize the plan, also better dose homogeneity was achieved- dose in the target volume ranging from $-5 \%$ to $+7 \%$, in accordance with the ICRU-50 recommendations. Internal mammary lymph nodes was contoured (IMLNs) according to the Radiation Therapy Oncology Group (RTOG) recommendations: inclusion of the IMLNs from the upper aspect of the medial first rib to the upper aspect of the fourth rib, ipsilateral to the treatment site, with a radial margin of $0.5 \mathrm{~cm}(\mathbf{1 0})$. Incidental internal mammary irradiation plan was defined as the plan that optimized to cover chest wall or whole breast CTV irrespective to IMLN CTV (done before IMLN CTV contouring). Intended internal mammary irradiation plan was defined as the plan that optimized to cover chest wall or whole breast
CTV and IMLN CTV (done after IMLN contouring), that was achieved through careful remodeling of incidental plan only by changing MLC to conform to IMLN CTV (i.e. wide tangential fields). Dosimetric evaluation of both plans was achieved, this includes all dose-volume histograms parameters to all contoured targeted and risk organ volumes include; IMLN CTV DVH parameters: total volume (cc), Dmean (mean dose in cGy), Dmin (minimum dose in cGy), Dmax (maximum dose in cGy), D95 (the dose in cGy delivered to $95 \%$ of the volume), D50 (the dose in cGy delivered to $50 \%$ of the IMLN volume), V45 (the volume as a percent of total volume receiving at least $45 \mathrm{~Gy}$, that is the minimal dose required for subclinical disease control) and V25 (the volume as a percent of total volume receiving at least 25 Gy, corresponding to the field borders). Chest wall or whole breast CTV DVH parameters: total volume, Dmean, D95 and V95. Axillary lymph nodes levels (I, II, and III) CTV DVH parameters: Total volume, Dmean and D90 (the dose in cGy delivered to $90 \%$ of the volume). Supraclavicular lymph node CTV DVH parameters: total volume, Dmean and D90. Lung (ipsilateral, contralateral and total): total volume, Dmean and V20 (the volume as a percent of total volume receiving at least 20Gy). Heart: total volume, Dmean and V40 (the volume as a percent of total volume receiving at least 40Gy) (10).

\section{Statistical Analysis}

All data were collected, tabulated and statistically analyzed using SPSS 22.0 for windows (SPSS Inc., Chicago, IL, USA) and Microsoft Office Excel 2010 for windows (Microsoft Cor., Redmond, WA, USA). Continuous variables were expressed as the mean \pm SD and the categorical variables were expressed as a number (percentage). Continuous variables were checked for normality by using Shapiro-Wilk test. Wilcoxon signed ranks test was used to compare two dependent groups of nonnormally distributed variables. All tests were two sided. p-value $<0.05$ was considered statistically significant, p-value $<0.001$ was considered highly statistically significant, and 
p-value $\geq 0.05$ was considered statistically insignificant (NS).

\section{RESULT}

\section{Basic characteristics}

Mean age was 48.47 and range between 28 years and 51 years, the most affected side was the left breast where 22 women out of 38 women $(57.9 \%)$ had left breast cancer (Table 1).

\section{Pathological findings}

The most frequent histopathological type was infiltrating ductal carcinoma. The most common grades were grade II and grade II. Mean tumor size was $33.08 \mathrm{~mm}$, the largest tumor size ranged from $5 \mathrm{~mm}$ up to $80 \mathrm{~mm}$. The most frequent $\mathrm{T}$ stage was $\mathrm{T} 2$ tumors. Mean number of positive axillary lymph nodes was about seven lymph nodes. The most common N stage was N2 disease. Stage III disease was considered the most frequent stage in the current study where it was present in $52.6 \%$ of patients, but further subclassification of stage groups revealed that the most common stage group was stage IIB where it was present in about $30 \%$ of patients. Positive estrogen receptor was present in twenty-seven patients $(71.1 \%)$. Positive progesterone receptor was present in twentyfour patients (63.2\%). Positive hormonal receptor was present in twenty-eight patients (73.7\%). Positive HER2/neu with IHC and/or FISH was present in twelve patients (31.6\%). Mean Ki67 index was about 27\%. According to this four immunohistochemical staining, the studied patients, it were classified into three molecular classes, luminal A/B class, the most common class, it was present in about three quarters of the studied patients (73.7\%) (Table 2).

\section{Management}

Modified radical mastectomy was the most frequent surgical treatment of the studied patients where twenty-seven patients $(71.1 \%)$ were operated by MRM while the remaining (28.9\%) were operated by breast conservative surgery (BCS). Only two patients (5.3\%) had received neoadjuvant chemotherapy. All patients except one patient had received adjuvant chemotherapy. The most commonly utilized regimen was 4 cycles of AC followed by 12 weeks of paclitaxel (Taxol®). Twentyeight patients $(73.7 \%)$ had started adjuvant hormonal treatment, $42.1 \%$ had started tamoxifen. Eleven patients (28.9\%) had started adjuvant trastuzumab (Herceptin $\left.{ }^{\circledR}\right)$ every three weeks. Twenty-seven patients (71.1\%) who were treated by MRM had received chest wall irradiation while eleven patients $(28.9 \%)$ who were treated by BCS had received whole breast irradiation. Thirty patients $(78.9 \%)$ had received also regional nodal irradiation of supraclavicular nodal irradiation with or without axillary lymph node irradiation. All patients were treated on linear accelerator photon beams, energy 6 or $15 \mathrm{MV}$. All patients had received 50Gy - 2Gy per fractions over 25 fractions in 5 weeks for chest wall or whole breast volume and regional nodal irradiation volumes. Patients who were treated by breast conservative treatment also received a tumor boost of $10 \mathrm{~Gy}$ - 2 Gy per fraction over 5 fractions in one week using electron of appropriate energy (Table 3).

\section{DVH parameters of IMLN CTV}

Mean internal mammary lymph node CTV volume was about $10 \mathrm{cc}$, ranged from $5 \mathrm{cc}$ up to $36 \mathrm{cc}$. Average of mean dose received by internal mammary lymph node (IMLN) CTV was significantly increased from $4581 \mathrm{cGy}$ in incidental plan to 5213.6 in intended plan (pvalue $<0.001$ ). Average of minimum dose received by internal mammary lymph node (IMLN) CTV was significantly increased from $1730.9 \mathrm{cGy}$ in incidental plan to 3439.6 cGy in intended plan (p-value<0.001). Average of maximum dose received by internal mammary lymph node (IMLN) CTV was significantly increased from $5527.4 \mathrm{cGy}$ in incidental plan to $5600.6 \mathrm{cGy}$ in intended plan (p-value $=0.001)$. Average of D95 of internal mammary lymph node (IMLN) CTV was significantly increased from 2421.5 cGy in incidental plan to $4156.5 \mathrm{cGy}$ in intended plan (p-value $<0.001$ ). Average of D50 of internal mammary lymph node (IMLN) CTV was significantly increased from $5005.2 \mathrm{cGy}$ in incidental plan to $5367.1 \mathrm{cGy}$ in intended plan (p-value $<0.001$ ). Average of V45 of internal mammary lymph node (IMLN) CTV 
was significantly increased from $73.8 \%$ in incidental plan to $92.8 \%$ in intended plan (pvalue $<0.001)$. Average of V25 of internal mammary lymph node (IMLN) CTV was significantly increased from $86.2 \%$ in incidental plan to $99.2 \%$ in intended plan (pvalue $<0.001$ ) (Table 4 and Figure 1).

\section{DVH parameters of organs at risk}

Comparison between incidental plan and intended plan as regards dose volume histogram (DVH) parameters of organs at risk among the studied breast cancer patients revealed average of mean dose to ipsilateral lung volume was significantly increased from 1985.7 cGy in incidental plan to 2229.6 in intended plan ( $p$-value $<0.001$ ). Average of V20 of ipsilateral lung volume was significantly increased from $37.7 \%$ in incidental plan to $43.05 \%$ in intended plan (pvalue $<0.001$ ). Average of mean dose to contralateral lung volume was significantly increased from $88.1 \mathrm{cGy}$ in incidental plan to 109.6 cGy in intended plan (p-value<0.001). Average of V20 of contralateral lung volume was significantly increased from $0.19 \%$ in incidental plan to $0.28 \%$ in intended plan (pvalue $=0.038$ ). Average of mean dose to total lung volume was significantly increased from 1032.02 cGy in incidental plan to $1163.6 \mathrm{cGy}$ in intended plan ( $p$-value $<0.001)$. Average of V20 of total lung volume was significantly increased from $18.9 \%$ in incidental plan to $21.4 \%$ in intended plan ( $\mathrm{p}$-value=0.038). Average of mean dose to heart volume was significantly increased from $935.5 \mathrm{cGy}$ in incidental plan to $1013 \mathrm{cGy}$ in intended plan $(p$-value $=0.025)$. Average of V40 of heart volume was significantly increased from $10.8 \%$ in incidental plan to $12 \%$ in intended plan $(\mathrm{p}$-value $=0.002)($ Table 5).

Table (1): Basic characteristics of the studied breast cancer patients.

\begin{tabular}{|c|c|c|}
\hline \multirow[t]{2}{*}{ Basic characteristics } & \multicolumn{2}{|c|}{$\begin{array}{l}\text { The studied breast cancer patients } \\
\qquad(\mathrm{N}=38)\end{array}$} \\
\hline & Number & Percent \\
\hline \multicolumn{3}{|l|}{ Age (years) } \\
\hline Mean \pm SD & \multicolumn{2}{|c|}{$48.47 \pm 10.80$} \\
\hline Median (Range) & \multicolumn{2}{|c|}{$51(28-65)$} \\
\hline \multicolumn{3}{|l|}{ Menopausal status } \\
\hline Premenopausal & 19 & $50 \%$ \\
\hline Postmenopausal & 19 & $50 \%$ \\
\hline \multicolumn{3}{|l|}{ Affected side } \\
\hline Right breast cancer & 16 & $42.1 \%$ \\
\hline Left breast cancer & 22 & $57.9 \%$ \\
\hline \multicolumn{3}{|l|}{ Site } \\
\hline Upper outer quadrant & 30 & $78.9 \%$ \\
\hline Lower outer quadrant & 4 & $10.5 \%$ \\
\hline Upper inner quadrant & 3 & $7.9 \%$ \\
\hline Lower inner quadrant & 1 & $2.6 \%$ \\
\hline
\end{tabular}


Table (2): Pathological findings of the studied breast cancer patients.

\begin{tabular}{|c|c|c|}
\hline \multirow[t]{2}{*}{ Pathological findings } & \multicolumn{2}{|c|}{$\begin{array}{l}\text { The studied breast cancer patients } \\
\qquad(\mathrm{N}=38)\end{array}$} \\
\hline & Number & Percent \\
\hline \multicolumn{3}{|l|}{ Histopathological type } \\
\hline Infiltrating ductal carcinoma & 35 & $92.1 \%$ \\
\hline Infiltrating lobular carcinoma & 3 & $7.9 \%$ \\
\hline \multicolumn{3}{|l|}{ Grade } \\
\hline Grade I & 1 & $2.6 \%$ \\
\hline Grade II & 18 & $47.4 \%$ \\
\hline Grade III & 17 & $44.7 \%$ \\
\hline N/A & 2 & $5.3 \%$ \\
\hline \multicolumn{3}{|l|}{ Peri neural invasion } \\
\hline Absent & 37 & $97.4 \%$ \\
\hline Present & 1 & $2.6 \%$ \\
\hline \multicolumn{3}{|l|}{ Lymphovascular invasion } \\
\hline Absent & 33 & $86.8 \%$ \\
\hline Present & 5 & $13.2 \%$ \\
\hline \multicolumn{3}{|l|}{ Extensive intraductal component } \\
\hline Absent & 37 & $97.4 \%$ \\
\hline Present & 1 & $2.6 \%$ \\
\hline \multicolumn{3}{|l|}{ Nipple } \\
\hline Free & 35 & $92.1 \%$ \\
\hline Paget's disease & 3 & $7.9 \%$ \\
\hline \multicolumn{3}{|l|}{ Skin invasion } \\
\hline Absent & 35 & $92.1 \%$ \\
\hline Present & 3 & $7.9 \%$ \\
\hline \multicolumn{3}{|l|}{ Multifocality/Multicentricity } \\
\hline Absent & 30 & $78.9 \%$ \\
\hline Present & 8 & $21.1 \%$ \\
\hline \multicolumn{3}{|l|}{ Tumor size (mm) } \\
\hline Mean \pm SD & \multicolumn{2}{|c|}{$33.08 \pm 17.83$} \\
\hline Median (Range) & \multicolumn{2}{|c|}{$30(5-80)$} \\
\hline \multicolumn{3}{|l|}{$\underline{\text { T stage }}$} \\
\hline $\mathrm{T} 1$ & 9 & $23.7 \%$ \\
\hline $\mathrm{T} 2$ & 22 & $57.9 \%$ \\
\hline T3 & 4 & $10.5 \%$ \\
\hline $\mathrm{T} 4$ & 3 & $7.9 \%$ \\
\hline \multicolumn{3}{|l|}{ Number of dissected nodes } \\
\hline Mean \pm SD & \multicolumn{2}{|c|}{$17.82 \pm 7.89$} \\
\hline Median (Range) & \multicolumn{2}{|c|}{$17.50(0-33)$} \\
\hline \multicolumn{3}{|l|}{ Number of positive nodes } \\
\hline Mean \pm SD & \multicolumn{2}{|c|}{$7.24 \pm 9.29$} \\
\hline Median (Range) & \multicolumn{2}{|c|}{$3(0-33)$} \\
\hline
\end{tabular}


Table (2): Continue.

\begin{tabular}{|c|c|c|}
\hline \multirow[t]{2}{*}{ Pathological findings } & \multicolumn{2}{|c|}{$\begin{array}{l}\text { The studied breast cancer patients } \\
\qquad(\mathrm{N}=38)\end{array}$} \\
\hline & Number & Percent \\
\hline \multicolumn{3}{|l|}{$\underline{N \text { stage }}$} \\
\hline N0 & 6 & $15.8 \%$ \\
\hline N1 & 15 & $39.5 \%$ \\
\hline $\mathrm{N} 2$ & 5 & $13.2 \%$ \\
\hline N3 & 11 & $28.9 \%$ \\
\hline $\mathrm{Nx}$ & 1 & $2.6 \%$ \\
\hline \multicolumn{3}{|c|}{ Lymph node capsule invasion } \\
\hline Absent & 32 & $84.2 \%$ \\
\hline Present & 6 & $15.8 \%$ \\
\hline \multicolumn{3}{|l|}{ AJCC TNM stage } \\
\hline Stage I & 4 & $10.5 \%$ \\
\hline Stage II & 14 & $36.8 \%$ \\
\hline Stage III & 20 & $52.6 \%$ \\
\hline \multicolumn{3}{|l|}{$\underline{\text { AJCC TNM stage }}$} \\
\hline Stage IA & 4 & $10.5 \%$ \\
\hline Stage IB & 0 & $0 \%$ \\
\hline Stage IIA & 2 & $5.3 \%$ \\
\hline Stage IIB & 12 & $31.6 \%$ \\
\hline Stage IIIA & 6 & $15.8 \%$ \\
\hline Stage IIIB & 3 & $7.9 \%$ \\
\hline Stage IIIC & 11 & $28.9 \%$ \\
\hline \multicolumn{3}{|l|}{ Estrogen receptor (ER) } \\
\hline Negative & 11 & $28.9 \%$ \\
\hline Positive & 27 & $71.1 \%$ \\
\hline \multicolumn{3}{|c|}{ Progesterone receptor (PR) } \\
\hline Negative & 14 & $36.8 \%$ \\
\hline Positive & 24 & $63.2 \%$ \\
\hline \multicolumn{3}{|l|}{$\underline{\text { Hormone receptor (HR) }}$} \\
\hline Negative & 10 & $26.3 \%$ \\
\hline Positive & 28 & $73.7 \%$ \\
\hline \multicolumn{3}{|l|}{ HER2/neu } \\
\hline Negative & 26 & $68.4 \%$ \\
\hline Positive & 12 & $31.6 \%$ \\
\hline \multicolumn{3}{|l|}{$\underline{\text { Ki67 index }}$} \\
\hline Mean \pm SD & \multicolumn{2}{|c|}{$27.31 \pm 23.94$} \\
\hline Median (Range) & \multicolumn{2}{|c|}{$20(5-100)$} \\
\hline \multicolumn{3}{|l|}{ Molecular subtype } \\
\hline Luminal A/B & 28 & $73.7 \%$ \\
\hline HER2 enriched & 4 & $10.5 \%$ \\
\hline Triple negative & 6 & $15.8 \%$ \\
\hline
\end{tabular}


Table (3): Management of the studied breast cancer patients.

\begin{tabular}{|c|c|c|}
\hline \multirow[t]{2}{*}{ Treatment } & \multicolumn{2}{|c|}{$\begin{array}{l}\text { The studied breast cancer patients } \\
\qquad(\mathrm{N}=38)\end{array}$} \\
\hline & Number & Percent \\
\hline \multicolumn{3}{|l|}{ Surgical treatment } \\
\hline Breast Conservative Surgery & 11 & $28.9 \%$ \\
\hline Modified Radical Mastectomy & 27 & $71.1 \%$ \\
\hline \multicolumn{3}{|l|}{ Neoadjuvant chemotherapy } \\
\hline No & 36 & $94.7 \%$ \\
\hline Yes & 2 & $5.3 \%$ \\
\hline 4AC-4Taxotere & 1 & $2.6 \%$ \\
\hline 6FEC100 & 1 & $2.6 \%$ \\
\hline \multicolumn{3}{|l|}{ Adjuvant chemotherapy } \\
\hline No & 1 & $2.6 \%$ \\
\hline Yes & 37 & $97.4 \%$ \\
\hline $4 \mathrm{EC}$ & 1 & $2.6 \%$ \\
\hline $6 \mathrm{EC}$ & 1 & $2.6 \%$ \\
\hline $6 \mathrm{FAC}$ & 4 & $10.5 \%$ \\
\hline $6 \mathrm{FEC} 75$ & 1 & $2.6 \%$ \\
\hline 4Taxol & 1 & $2.6 \%$ \\
\hline 4AC-12wTaxol & 22 & $57.9 \%$ \\
\hline 4AC-4Taxol & 1 & $2.6 \%$ \\
\hline 4FAC-12wTaxol & 2 & $5.3 \%$ \\
\hline 4FAC-4Taxol & 1 & $2.6 \%$ \\
\hline 4AC-4Taxotere & 3 & $7.9 \%$ \\
\hline \multicolumn{3}{|l|}{ Adjuvant hormonal treatment } \\
\hline No & 10 & $26.3 \%$ \\
\hline Yes & 28 & $73.7 \%$ \\
\hline Tamoxifen & 16 & $42.1 \%$ \\
\hline Aromatase Inhibitors (AI) & 12 & $31.6 \%$ \\
\hline \multicolumn{3}{|l|}{ Adjuvant Trastuzumab treatment } \\
\hline No & 27 & $71.1 \%$ \\
\hline Yes & 11 & $28.9 \%$ \\
\hline \multicolumn{3}{|l|}{ Radiotherapy sitting } \\
\hline Whole breast irradiation & 11 & $28.9 \%$ \\
\hline Chest wall irradiation & 27 & $71.1 \%$ \\
\hline \multicolumn{3}{|l|}{$\underline{\text { Regional nodal irradiation }}$} \\
\hline No & 8 & $21.1 \%$ \\
\hline Yes & 30 & $78.9 \%$ \\
\hline
\end{tabular}


Table (4): Comparison between incidental plan and intended plan as regards dose volume histogram (DVH) parameters of internal mammary lymph node (IMLN) CTV among the studied breast cancer patients.

\begin{tabular}{|l|c|c|c|}
\hline IMLN CTV & $\begin{array}{c}\text { Incidental plan } \\
(\mathbf{N = 3 8 )} \\
\text { Mean } \pm \text { SD }\end{array}$ & $\begin{array}{c}\text { Intended plan } \\
(\mathbf{N = 3 8 )} \\
\text { Mean } \pm \text { SD }\end{array}$ & p-value• \\
\hline Mean dose (cGy) & $4581.02 \pm 721.93$ & $5213.60 \pm 248.57$ & $<0.001$ \\
\hline Min. dose (cGy) & $1730.92 \pm 1514.77$ & $3439.65 \pm 111.14$ & $<0.001$ \\
\hline Max. dose (cGy) & $5527.44 \pm 207.20$ & $5600.63 \pm 276.70$ & 0.001 \\
\hline D95 (cGy) & $2421.57 \pm 1810.50$ & $4156.57 \pm 880.89$ & $<0.001$ \\
\hline D50 (cGy) & $5005.26 \pm 644.39$ & $5367.10 \pm 229.35$ & $<0.001$ \\
\hline V45 (\%) & $73.81 \pm 22.40$ & $92.68 \pm 6.57$ & $<0.001$ \\
\hline V25 (\%) & $86.28 \pm 14.04$ & $99.28 \pm 1.90$ & $<0.001$ \\
\hline
\end{tabular}

- Wilcoxon signed ranks test; $p$-value $<0.05$ is significant.

Table (5): Comparison between incidental plan and intended plans as regard dose volume histogram (DVH) parameters of organs at risk among the studied breast cancer patients.

\begin{tabular}{|l|c|c|c|}
\hline Organs at risk & $\begin{array}{c}\text { Incidental plan } \\
(\mathbf{N}=38) \\
\text { Mean } \pm \text { SD }\end{array}$ & $\begin{array}{c}\text { Intended plan } \\
(\mathbf{N = 3 8 )} \\
\text { Mean } \pm \text { SD }\end{array}$ & p-value \\
\hline Ipsilateral lung mean dose (cGy) & $1985.71 \pm 451.99$ & $2229.68 \pm 413.54$ & $<0.001$ \\
\hline Ipsilateral lung V20 (\%) & $37.78 \pm 8.72$ & $43.05 \pm 7.70$ & $<0.001$ \\
\hline Contralateral Lung mean dose (cGy) & $88.10 \pm 46.93$ & $109.63 \pm 48.76$ & $<0.001$ \\
\hline Contralateral Lung V20 (\%) & $0.19 \pm 0.68$ & $0.28 \pm 0.70$ & 0.038 \\
\hline Total lung mean dose (cGy) & $1032.02 \pm 271.49$ & $1163.60 \pm 262.15$ & $<0.001$ \\
\hline Total lung V20(\%) & $18.94 \pm 5.46$ & $21.47 \pm 4.87$ & $<0.001$ \\
\hline Heart mean dose (cGy) & $935.55 \pm 682.89$ & $1013 \pm 706.93$ & 0.025 \\
\hline Heart V40 (\%) & $10.81 \pm 12.21$ & $12 \pm 12.88$ & 0.002 \\
\hline
\end{tabular}

- Wilcoxon signed ranks test; $\mathrm{p}$-value $<0.05$ is significant.

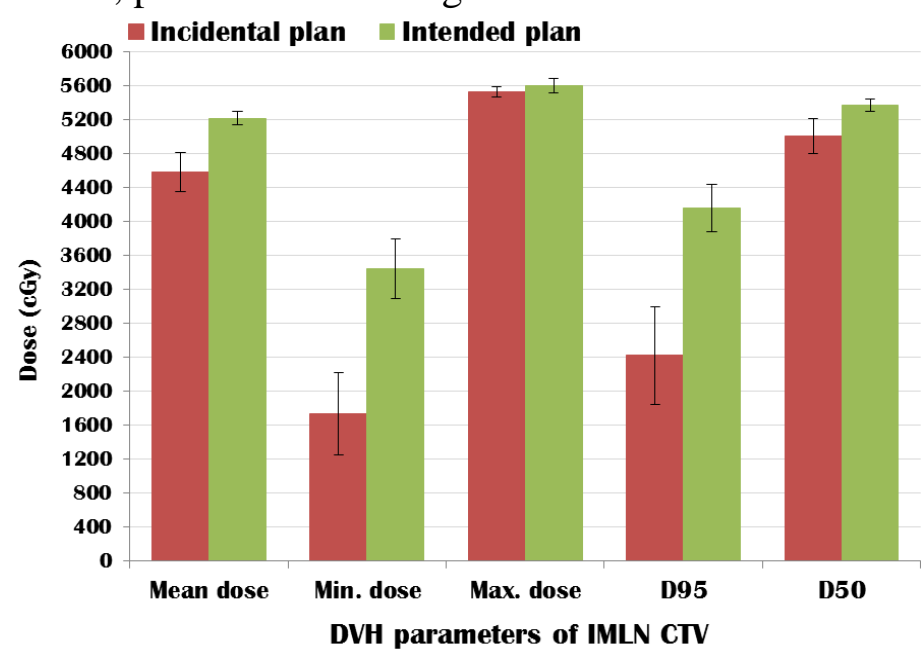

Figure (1): Error Bar chart show comparison between incidental plan and intended plan regarding DVH parameters (Mean dose, Min. dose, Max. dose, D95 and D50) of IMLN CTV; bar represents mean, Y-error bar represents 95\%CI (Confidence interval of mean). 


\section{DISCUSSION}

The second draining pathway of breast cancer is internal mammary lymph nodes (IM). Involvement of axillary lymph nodes raises possibility of IM involvement as in patients with negative axillary nodes, have probability of $4-9 \%$ to have positive IM nodes while patients with axillary positive nodes, have probability of $16.52 \%$ to have positive IM nodes (4). Internal mammary lymph node irradiation is a matter of debate while postmastectomy or post-lumpectomy radiotherapy to the chest wall and/or breast and axillary and/or supraclavicular lymph nodes was shown to improve overall survival in early breast cancer (6). In EBCTCG metaanalysis, there was no benefit for radiotherapy in patients with node-negative disease while $7.9 \%$ absolute reduction at twenty years in patients with 1-3 positive axillary lymph nodes and found $9.3 \%$ reduction in patients with 4 or more positive axillary nodes (7). Incidental irradiation of lymph node can be occured during conformal three-dimensional chest wall and/or breast irradiation (8). In the present study, mean age was 48.47 and range between 28 years and 51 years, the most affected side was the left breast where 22 women out of 38 women (57.9\%) had left breast cancer. This was concordant with a study was done by Leite ETT, et al. (9) in which the most affected side was the left breast where 45 women out of 80 women (56.3\%) had left breast cancer. Stage III disease was considered the most frequent stage in the current study where it was present in $52.6 \%$ of patients, but further Subclassification of stage groups revealed that the most common stage group was stage IIB where it was present in about $30 \%$ of patients while Leite ETT, et al. in their study in 2016 showed that the most frequent stage was stage IA where 32 out of 80 patients $(40 \%)$ had that stage (9). In the present study modified radical mastectomy was the most frequent surgical treatment of the studied patients where twenty-seven patients $(71.1 \%)$ were operated by MRM while the remaining (28.9\%) were operated by breast conservative surgery (BCS). This was discordant with the study that was done by Leite ETT, et al. in 2016 which revealed that the breast conserving surgery was the most frequent type of surgery utilized in their cohort, where 58 out of 80 patients $(72.5 \%)$ underwent breast conserving surgery (9). In the current study, mean internal mammary lymph node CTV volume was about $10 \mathrm{cc}$, ranged from 5 cc up to 36 cc while Leite ETT, et al. in 2016 reported in their study that the mean IMLN volume was $6.8 \mathrm{~mL}$ in $2 \mathrm{D}$ treatment and 5.9 $\mathrm{mL}$ in $3 \mathrm{D}$ treatment, the minimum volume in both groups was $4.4 \mathrm{~mL}$ and the maximum volume in both groups was $8.1 \mathrm{~mL}(\mathbf{9})$. In the present study, average of mean dose received by internal mammary lymph node (IMLN) CTV was significantly increased from 4581 cGy in incidental plan to 5213.6 in intended plan (p-value $<0.001$ ) while Leite ETT, et al. in 2016 reported in their study that mean dose in 3D treatment was significantly higher than 2D treatment where average was 2064.2 cGy versus 793.5 cGy respectively (9). In the present study, average of minimum dose received by internal mammary lymph node (IMLN) CTV was significantly increased from $1730.9 \mathrm{cGy}$ in incidental plan to 3439.6 cGy in intended plan ( $\mathrm{p}$-value $<0.001$ ) while Leite ETT, et al. in 2016 reported in their study that minimum dose in 3D treatment was significantly higher than 2D treatment where average was 1790 cGy versus 639.5 cGy respectively (9). In the present study, average of maximum dose received by internal mammary lymph node (IMLN) CTV was significantly increased from 5527.4 cGy in incidental plan to $5600.6 \mathrm{cGy}$ in intended plan (p-value $=0.001)$ while Leite ETT, et al. in 2016 reported in their study that maximum dose in 3D treatment was significantly higher than 2D treatment where average was 4198.3 cGy versus 2827.7 cGy respectively (9). In the present study, average of D95 of internal mammary lymph node (IMLN) CTV was significantly increased from 2421.5 cGy in incidental plan to $4156.5 \mathrm{cGy}$ in intended plan (p-value<0.001) while Leite ETT, et al. in 2016 reported in their study that D95 in 3D treatment was significantly higher than 2D treatment where average was $753 \mathrm{cGy}$ versus 
228.1 cGy respectively (9). In the present study, average of D50 of internal mammary lymph node (IMLN) CTV was significantly increased from 5005.2 cGy in incidental plan to 5367.1 cGy in intended plan (pvalue $<0.001$ ) while Leite ETT, et al. in 2016 reported in their study that D50 in 3D treatment was significantly higher than 2D treatment where average was $1746.7 \mathrm{cGy}$ versus 619.7 cGy respectively (9). In the present study, average of V45 of internal mammary lymph node (IMLN) CTV was significantly increased from $73.8 \%$ in incidental plan to $92.8 \%$ in intended plan (pvalue<0.001) while Leite ETT, et al. in 2016 reported in their study that V45 in 3D treatment was significantly higher than 2D treatment where average was $15.8 \%$ versus $2.2 \%$ respectively (9). In the present study, average of V25 of internal mammary lymph node (IMLN) CTV was significantly increased from $86.2 \%$ in incidental plan to $99.2 \%$ in intended plan ( $p$-value $<0.001)$ while Leite ETT, et al. in 2016 reported in their study that V25 in 3D treatment was significantly higher than 2D treatment where average was $31.9 \%$ versus $7.8 \%$ respectively (9).

\section{CONCLUSION}

Our result confirm that incidental irradiation of internal mammary lymph nodes is not sufficient to cover that volume properly and intended irradiation is required for this purpose but this comes in expense of increasing both lungs and heart toxicities, so we recommend to irradiate internal mammary lymph nodes in breast cancer patients with indication for internal mammary irradiation and not to use wide tangential technique however you should use alternative strategies to be sure that lungs and heart doses and consequence toxicities are minimal as possible. Small sample size and including patients without indication for internal mammary irradiation are the principle drawbacks of our study, also the major limitation of our study is that we use wide tangential field design for intended irradiation, so we also advice that similar study with larger sample size, including only patients with indication for internal mammary irradiation and using photon/electron direct field for intended irradiation should be conducted in our department to solve this debates.

\section{Declaration of interest and Funding information}

The authors report no conflicts of interest.

\section{Contributors}

All authors have participated in the research and article preparation. All authors have approved the final article

\section{Authorship}

All authors have substantial contributions to all of the following: (1) the conception and design of the study, or acquisition of data, or analysis and interpretation of data, (2) drafting the article or revising it critically for important intellectual content, (3) final approval of the version to be submitted.

\section{Declaration of interest}

The authors report no conflicts of interest. The authors alone are responsible for the content and writing of the paper.

Funding information None declared

\section{REFERNCES}

1. Ibrahim AS and Mikhail NNH. Review Article: The Evolution of Cancer Registration in Egypt: From Proportions to Population-based Incidence Rates. SECI Oncology, Volume: 2015; Publication ID: 4.

2. Whelan TJ, Pignol J-P, Levine MN, Julian JA, MacKenzie R, Parpia S, et al. Longterm results of hypofractionated radiation therapy for breast cancer. N Engl J Med 2010; 362(6):513-520

3. Aleknavičius E, Atkočius V, Kuzmickienė I and Steponavičienè R. Postmastectomy internal mammary nodal irradiation: a longterm outcome. Medicina (Kaunas). 2014; 50(4):230-6.

4. Oscar M, Irma H, Philip P, Laurence C, Henk S, Walter V-D-B, et al., For The EORTC Radiation Oncology and Breast Cancer Groups, Toxicity at three years with and without irradiation of the internal mammary and medial supraclavicular lymph node chain in stage I to III breast cancer (EORTC trial 22922/10925), Acta Oncologica. 2010; 49:1, 24-34.

5. Huang O, Wang L, Shen K, Lin H, Hu Z, 
Liu G, et al. Breast cancer subpopulation with high risk of internal mammary lymph nodes metastasis: Analysis of 2,269 Chinese breast cancer patients treated with extended radical mastectomy. Breast Cancer Res Treat 2008; 107:379-87.

6. Thorsen LB, Offersen BV, Danø H, Berg M, Jensen I, Pedersen AN, et al. DBCG-IMN: A Population-Based Cohort Study on the Effect of Internal Mammary Node Irradiation in Early Node-Positive Breast Cancer. J Clin Oncol. 2016; Feb 1; 34(4):314-20.

7. McGale P, Taylor C, Correa C, Cutter D, Duane F, Ewertz M, et al. Effect of radiotherapy after mastectomy and axillary surgery on 10-year recurrence and 20-year breast cancer mortality: meta-analysis of individual patient data for 8135 women in 22 randomised trials. Lancet 2014;
383:2127-2135

8. Bonavitacola P, Sioshansi S, Rava PS and Fitzgerald T. Incidental axillary coverage comparison between 3DCRT and hybrid IMRT for whole breast irradiation. Int $\mathrm{J}$ Radiat Oncol Biol Phys. 2012; 84(3 Suppl): S228.

9. Leite ETT, Ugino RT, Santana MA, Ferreira DV, Lopes MR, Pelosi EL, et al. Incidental irradiation of internal mammary lymph nodes in breast cancer: conventional twodimensional radiotherapy versus conformal three-dimensional radiotherapy. Radiol Bras. 2016 Mai/Jun;49(3):170-175.

10. Julia W, An T, Douglas A, Thomas B, Shannon MD, Lawrence M et al. "Breast Cancer Contouring Atlas". Available at: https://www.rtog.org/CoreLab/Contouring Atlases/BreastCancerAtlas.aspx.

To Cite This Article: El-Drgham YT, -hosainy AA, Mounir H, Bayomy MF, Intended 3D conformal irradiation of internal mammary lymph node is better than incidental irradiation in breast cancer patients, ZUMJ 2020; 26 (2):344-355, Doi: 10.21608/zumj.2019.14223.1296 